\section{Factors Influencing Social Media Addiction among G.C.E. Advanced Level Students in Sri Lanka: A Case Study in Colombo District, Sri Lanka}

Wickramasurendra, J.M. ${ }^{1 *}$, Jagoda, D. J. ${ }^{1}$ and Rathnayake, R.M.L. ${ }^{1}$

${ }^{1}$ Department of Economics and Statistics, Sabaragamuwa University of Sri Lanka, Belihuloya, 70140, Sri Lanka.
Sri Lanka Journal of Social Sciences and Humanities Volume 1 Issue 2, August 2021: 1-11 ISSN: $2773692 X$ (Online), 27736911 (Print) Copyright: (C) 2021 The Author(s)

Published by Faculty of Social Sciences and Languages, Sabaragamuwa University of Sri Lanka Website: https://www.sab.ac.lk/sljssh DOI: http://doi.org/10.4038/sljssh.v1i2.33

Received: 20 November, 2020, Revised: 02 March, 2020, Accepted: 16 April, 2021

How to Cite this Article: Wickramasurendra, J.M., Jagoda, D. J. \& Rathnayake, R.M.L. (2021). Factors influencing social media addiction among G.C.E. advanced level students in Sri Lanka: A case study in Colombo district, Sri Lanka. Sri Lanka Journal of Social Sciences and Humanities, 1(2), 1-11.

\begin{abstract}
Social Media Addiction is regarded as a form of psychological or behavioral dependence on social media platforms driven by an obsessive, uncontrollable urge to use social media. Typically, young people addicted to social media are more likely to report poor mental health including psychological distress. Bergen Social Media Addiction Scale (BSMAS) is a distinct measurement used to evaluate the addiction level of a particular individual. According to Data Reportal (2020), social media penetration in Sri Lanka stands at 30 percent including a majority of youngsters. Since G.C.E. Advanced Level examination is a critical examination instrumental in pursuing higher education, it is of great importance to identify significant factors affecting social media addiction among Advanced Level students. A sample of 250 students was drawn using multi-stage clustering from Colombo district which recorded the highest internet usage in 2018. The primary data were collected through online and questionnaire surveys. To achieve the main objective, factor analysis and binary logistic regression were used. It was revealed that peer influence, entertainment, and owning a smartphone positively affected the total students' social media addiction. When it comes to female students, parent and peer utilization of social media and online interpersonal relationships were identified as important factors. Similarly, peer influence, subject stream, and owning a smartphone were identified as influential factors for male students' addiction. It was further revealed that male students who were studying in the art stream and technology stream had a higher possibility of addiction compared to that of the physical science stream. The overall research provides important recommendations on possible actions to prevent addiction.
\end{abstract}

Keywords: Binary Logistic Regression, G.C.E. Advanced Level Students, Social Media Addiction.

\section{INTRODUCTION}

From the beginning of humankind, man has been engaging in the exchange of various information, ideas, and attitudes interchangeably using signs and symbols. With the gradual civilization of primitive man, their methods of communication developed and information exchange was made frequent. Progressively, with the industrial revolution in the 1800 s, the budding digital era brought many extraordinary developments in technology that had its effect on multiple fields. Tyagi \& Soni (2019) emphasized that many changes and developments in the field of communication have emerged due to the penetration of smartphones in society. As a result, one of the recent most impactful technological phenomena was the emergence and spread of social media (Kane, Alavi, Labianca, \& Borgatti, 2014). The launching of Facebook in 2004 and Twitter in 2006 were considered major turning points in social media network history. Social Media is defined as websites that allow profile creation and visibility of relationships between users that provide opportunities for sharing relationships, groups, conversations, and profiles (Kietzmann, Hermkens, McCarthy \& Silvestre, 2011; Boyd \& Ellison, 2008). In the Sri Lankan context, as per the statistics of Napoleoncat (2020), Facebook usage among the age group of 13 to 17 is 5.4 percent and 18 to 24 is 27.9 percent. Furthermore, as specified by the statistics of the Telecommunications Regulatory Commission of Sri Lanka (TRCSL) 2018, there were 1.5 million social media users between the age of 10 and 18 of which the majority were from the Western province.

Despite the benefits social media networks have brought in all fields, many individuals are becoming obsessed with social media networks and fail to effectively manipulate this new technology. This condition is recognized in the literature as Social media addiction. The definitions of social media addiction include obsessive, uncontrollable thoughts about social media sites, and persistent uncontrollable use of social media (Bjornsen, 2018). According to Deng and Tevaras (2013), social media has become an integral part of a student's life. Studies on social media addiction among college students have highlighted its impact on their low academic performance. Moreover, prolonged use of social media may result in critical mental health problems such as stress, anxiety, depression, and negative influence on longterm well-being (Eraslan-Capan, 2015; Hong, Huang, Lin \& Chiu, 2014). As per Mediakix (2018), 210 million people are

\footnotetext{
* Corresponding author: Tel.: +94713581678; Email: jithmimanthila.jith@gmail.com

(iD) https://orcid.org/0000-0001-6564-1288
} 
estimated to suffer from internet and social media addictions worldwide and teens who spend an average of 5 hours a day on social media are twice more likely to exhibit depressive symptoms. The Bergen Social Media Addiction Scale (BSMAS) is used to measure social media addiction of a particular individual and a cut-off score of 19 points was suggested as the ideal threshold to classify individuals who are at-risk of problematic social media use (Bányai, Zsila, Király, Maraz, Elekes, Griffiths \& Demetrovics, 2017).

Considering the G.C.E Advanced Level, it is an extremely competitive examination that is instrumental in the pursuit of a student's higher education and future career. It has been proved by the performance reports of the Ministry of Education (2018) that during the past few years, the performance of students in G.C.E. Advanced Level examination has been steadily declining. Since the usage of social media has gone up during the recent past, the younger generation tends to move away from general society, spend time with social media ensuing lower academic success. This may consequently result in the degradation of the young generation who will move into the national workforce and subsequently slower the overall long-term GDP (Gross Domestic Production) growth rate of the country and also lower the level of civic participation.

Social media is addictive both physically and psychologically. As a result, many allegations and issues have arisen in this regard. Most of the previous studies have highlighted the potential negative effects of excessively using social media sites. Studies on social media addiction among college students have highlighted its impact on their low academic performance as well. Suicides and other mental health problems propagated by social media among the young generation are also being a global issue. It has been reported by The Guardian (n.d.) that a 17 years old teenage girl in India killed herself after her parents ban her from using Facebook. A 16year-old girl has reportedly killed herself in Malaysia, after posting a poll on her Instagram account asking followers if she should die or not. It is emphasized that even suicides have been attributed due to the conflicts that arose from excessive social media use. Thereby, social media addiction has become one of the critical issues among adolescents in modern society.

The findings of the study are of particular interest to those who are involved in the social and educational development of children at present and in the future. Further, the findings of this study are particularly important to the parents and by initiating to eliminate the addiction behaviors of adolescents, students' Advanced level results can be improved. The study is supposed to offer the findings critical to limit the use of social media for better academic achievements. Through this study, a new researcher can get an idea of the most influencing factors for social media addiction among adolescents. Moreover, the findings may provide practical insights on how to use children's attitudes toward social media for the improvements in social networking sites. The findings are of practical relevance to those who are responsible for the provision, development, and operation of social network sites and the policymakers who are responsible for regulating the social media platforms. Therefore, it is of great importance to explore the factors affecting students' social media addiction. Especially in the case of Advanced Level students who have been displaying low academic performance, there is reason to suspect certain levels of addiction among them, be it direct or indirect. Thus, the main objec- tive of the present study is to investigate the significant factors that affect social media addiction among G.C.E. Advanced level students in Sri Lanka.

This paper is organized into five sections in which the first section has been already presented with the background, research problem, the importance of the study, and the main objective. The second section includes a literature review; the most relevant theories related to the study and the empirical, methodological literature which depends upon historical shreds of evidence related to the topic. In the third section, conceptual framework and methodology are acknowledged. This section describes the methodology used to test the hypotheses, the dependent variable, and the independent variable. Data presentation and analysis are presented and justified in section four. It consists of the visual representation of the data and the statistical analysis for collected data. In the data presentation, graphs and tabulations are used. In the end, the fifth section includes the conclusions and the recommendations which are drawn by the results of the analysis.

\section{LITERATURE REVIEW}

Three basic components of attitude towards the use of technology, perceived usefulness, and perceived ease of use were proposed by Davis (1989) in his previous study as being important constructs affecting social media addiction. Usually, a child is surrounded by an inner circle of relationships involving parents, siblings, and peers. This inner circle has an important influence on a child (Lewis, 2005). Consequently, perceived parent influence and perceived peer influence were included as important constructs in the study with direct and indirect influences on the child's attitude toward the use of the technology (Kristianto, 2017). Generally, children stay online mainly for three reasons: entertainment, socializing, and information seeking (Lwin, Li \& Ang, 2012). As per the study of Kristianto (2017), six important influencing factors were identified on attitudes of children to the use of social networking sites: perceived ease of use, flow experience, technology self-efficacy, perceived usefulness, risk, and technology accessibility followed by three less important effects due to technology experience, perceived parent influence, and perceived peer influence. Al-Menayes (2015) indicated that the amount of time spent using social media and the satisfaction gained via the use of it is positively correlated with all factors of social media. This defines that individual reporting signs of addiction are more likely to be satisfied with the functions social media provide.

Shahghasemi \& Emamzadeh (2019) stated that females use social media more than the male peers, religious people usually tend to use social media more frequently than non-religious ones, and those who live together with their partners, the separated people and people who were unmarried use social media much more than married people. As noted by Kavčič, Zupančič, Poredoš, \& Bjornsen (2019), problematic behaviors associated with social media and mobile phone use, except for catfishing, are comparatively common among the young generation and the examined behaviors were negatively associated with age while overuse of mobile phones, social media, and creeping was more prevalent in females than males.

Athukorala (2018) stated that the major contributing factors for the use of social media sites by the international and local students of Wuhan University China were privacy, convenience, and time spent. The researcher further assessed that the major concerns of students in using social media 
can be categorized into two types of phenomena as socioeconomic factors and demographic factors. This research was focused on factors regarding usage of social media and factors influencing international and local students' perception of social media. The research found that there was a huge impact of influencing factors on the use of social media by local as well as international students. Although all factors were mentioned as influencing factors, it was found that legal risk seemed to affect both groups of students very effectively. Furthermore, the researcher emphasized that students heavily depend on social media for learning, research needs, and their daily life. He stressed that it is important to integrate social media literacy education into academic and professional development programs. According to Yahya \& Rahim (2017), the factors affecting social network addiction among adolescents in Asian countries were categorized into three different perspectives namely, information system, sociology, and psychology. As stated by Hawi \& Samaha (2016), addictive use of social media had a negative relationship with self-esteem, and the latter had a positive relationship with satisfaction with life. Moreover, it was found that self-esteem mediated the influence of social media addiction on satisfaction with life. Hou, Xiong, Jiang, Song \& Wang (2019) examined the impact of social media addiction on students' mental health and academic performance and the role of self-esteem as a mediator. Besides, the researchers tested the effectiveness of the intervention in social media addiction and its adverse outcomes. It was found that social media addiction was inversely associated with the student's mental health and academic performance mediated by self-esteem. Also, the results showed that the intervention was effective in reducing social media addiction and improving mental health and academic efficiency.

An increase in risk awareness regarding internet use among children confirmed that preteen age children were aware of risks of personal information disclosure, system security, data stealing, and contact with strangers (Livingstone, 2014; Shin \& Ismail, 2014). According to the study of Athukorala (2018) about factors affecting the use of social media by university students, it has been claimed that the main concerns in using social media are privacy and convenience. Online privacy has been defined by Sushko (2020) as how much of an individual's personal, financial, and browsing information remains private when he is online. According to Savci and Aysan (2016), it was revealed that loneliness significantly increases social media usage. Oktan (2015) also found that social media addiction was negatively related to psychological resilience; individuals who have limited interpersonal relations and cannot find the required support in real-life resort to social media to meet these needs, thus causing the addictive behavior. As per the study of Tyagi \& Soni (2019), addiction to smartphones (Nomo-phobia), disconnection with real relationships, obsessing virtual communication and tense family atmosphere were highlighted as main influencing factors for social media addiction. Addictive use of social media was positively related to being female and single, anxiety and levels of depression and age appeared to be inversely related to addictive use of social media networks. (Andreassen, Billieux, Kuss, Demetrovics, Mazzoni, Griffiths \& Pallesen, 2016). It is also clear that addiction to Facebook is positively associated with depression, anxiety, and insomnia (Koc \& Gulyagci, 2013), and negatively related to an individual's well-being, self-esteem, vigor, and life satisfaction (Samaha \& Hawi, 2017). Tutgun Ünal (2015) observed a positive association between hours spent on social media platforms and social media addiction.
The literature regarding social media addiction and its influence appears broadly worldwide. However, in the Sri Lankan context, there have been less sufficiently in-depth examinations on the factors affecting students' social media addiction. Further, this special reference to the Colombo district is a specific gap. In those studies, they were not going on for a large number of factors. Since this research gap has not been fully attained through previous research, the present study aims at filling the existing literature gap by assessing the factors affecting the social media addiction of Advanced level students in Sri Lanka.

\section{MATERIALS AND METHODS}

The population implemented in the study was G.C.E. Advanced Level students of grade 12 and 13 in government schools of Colombo district in 2020. According to the School Census Report of the Ministry of Education (2018), the total number of Advanced Level students of government schools in Colombo district was recorded as 60,745 . The respondents were distributed across five major subject streams: Physical Science stream, Biological Science stream, Commerce stream, Art stream, and Technology stream. A sample-sized 250 students were selected from the total population by using the multi-stage cluster sampling method.

The population was divided into multiple clusters based on educational zones and divisions. Random groups were selected on a school basis. In the first stage of clustering, the two educational zones, Colombo and Piliyandala, were selected randomly from Colombo district. As the next stage, the educational divisions Borella and Colombo South from Colombo zone and Kesbewa from Piliyandala zone were selected. From the selected educational divisions, a total of 10 schools were chosen randomly: Asoka Vidyalaya, Presbyterian Balika Vidyalaya and Yasodara Balika Vidyalaya from Borella division; Isipathana Vidyalaya, Mahanama Vidyalaya, Lumbini Vidyalaya and Sirimavo Bandaranayaka Vidyalaya from Colombo South division; Piliyandala Central College, Boralesgamuwa Maha Vidyalaya and East Arawwala Dharmapala Maha Vidyalaya from Kesbewa division. Then under the last stage, the researcher selected students stream-wise from each school in proportion to the total number of students studying in each subject stream in the population. In this study, random selection was performed using the lottery method.

Both primary and secondary data sources were used for the study. The researcher collected primary data from the sampled respondents through a questionnaire and online survey to accomplish the research objectives. Government-issued statistical data, website statistics, journal information, newspaper articles, and research articles were adopted to collect secondary data both manually and via electronic media. The researcher used 24 independent variables to conduct the study out of which 9 were categorical and 15 were continuous independent variables. The categorical explanatory variables were Age, Gender, Parents' Working Status, Residence Area, Subject Stream, Time Spent per day, Frequency of Use, Owning a Smartphone, and Technology Experience, and remaining variables were continuous.

The dependent variable "Social Media Addiction" was measured using the Bergen Social Media Addiction Scale (BSMAS) consisting of 6 questions. Bergen Social Media Addiction Scale (BSMAS; BaÂnyai, Zsila, KiraÂly, Maraz, Elekes, Griffiths, Andreassen \& Demetrovics, 2017) is used to measure the social media addiction of a particular individual. This present scale assesses social media use in general over the past 
12 months with six items in the scale of addictive behavior (i.e., salience, mood modification, tolerance, withdrawal symptoms, conflict, and relapse). The items were included as statements in the questionnaire,

1. I spend a lot of time thinking about social media or planned use of social media.

2. I feel an urge to use social media more and more.

3. I use social media to forget about personal problems.

4. I tried to cut down the use of social media but was unable to do so.

5. I become restless or troubled if I'm prohibited the use social media.
6. I use social media so much that it has negative impacts on my studies.

The six statements were to be answered on a 5-point Likert scale of "very rarely" to "very often". The individuals at or above cut-off score of 19 points were suggested as the ideal threshold who were classified as at-risk of problematic social media use (Bányai, Zsila, Király, Maraz, Elekes, Griffiths \& Demetrovics, 2017) That is, those who had scored at or above 19 were recognized as social media addicts and below 19 as social media non-addicts.

The conceptual framework of this research is demonstrated in figure 1.

Figure 1: Conceptualization

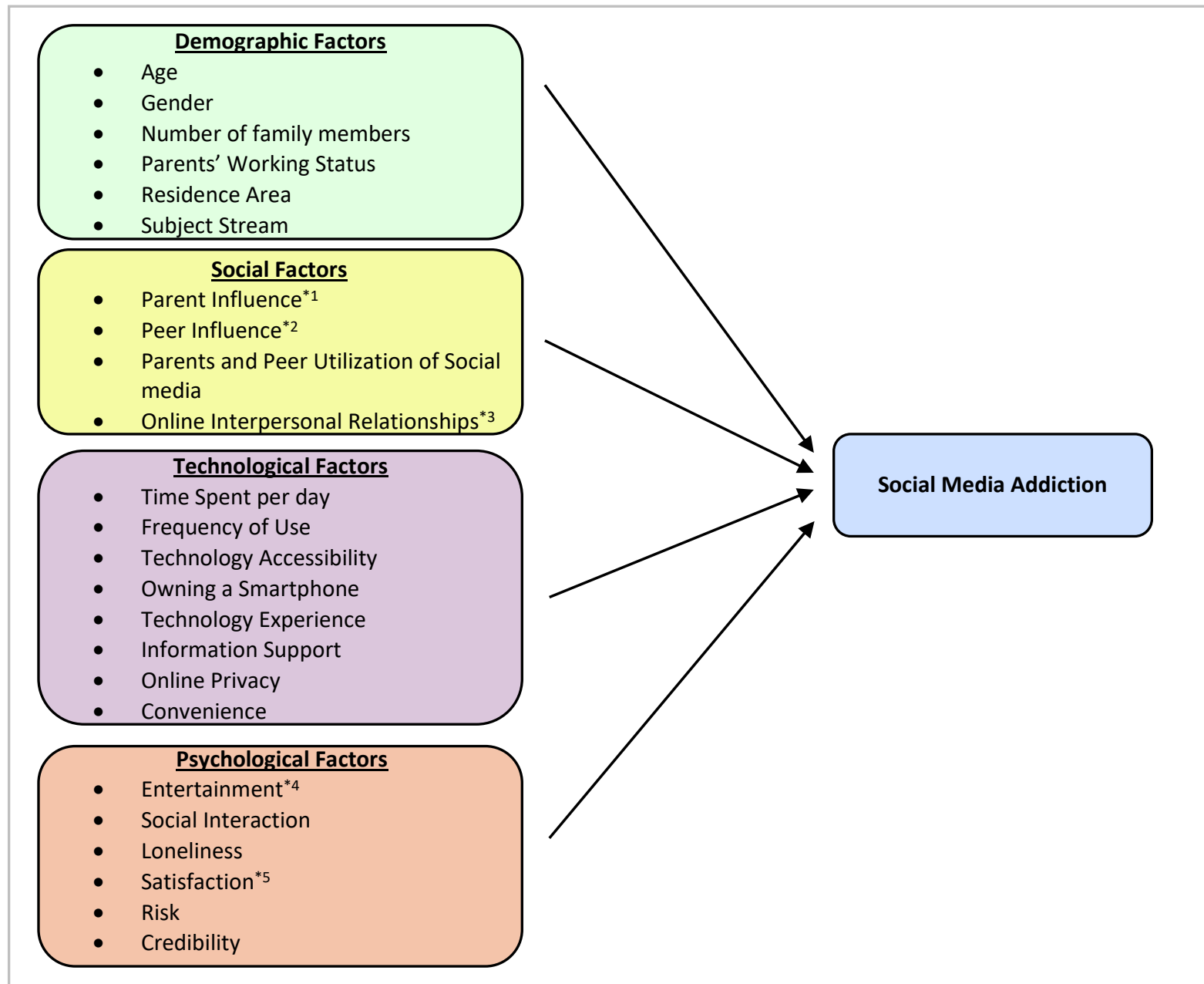

Source: Sample Survey 2020

*1 My parents have discussed with me what l've been doing online.

My parents have restricted me from using some social media sites.

My parents complain when I do something on social media that they dislike.

My parents use social media frequently

*2 I talk with my friends about social media posts and profiles.

My friends complain when I do something on social media that they dislike.

Most of my friends use social media.
*3 How many friends/ followers do you have in your social media accounts?

How many relationships do you have that are maintained exclusively via social media?

I prefer friendships on social media to friendships in real life.

I use social media to interact with society well.

*4 Using social media sites makes my life more interesting and fun.

I think my life would be empty, boring, and joyless without social media.

How happy are you with using social media?

*5 Level of satisfaction of using Social media. 
The collected data was analyzed using the Statistical Package of Social Sciences (SPSS) to determine the influential factors for social media addiction among students. Binary Logistic Regression model was used as the main data analysis technique along with factor analysis, correlation analysis, chi-squared test, and one-way ANOVA test.

\section{RESULTS AND DISCUSSION}

Table 1: Descriptive Statistics

\begin{tabular}{lll}
\hline Variable & Category & Proportion \\
\hline Gender & Male & $52.4 \%$ \\
& Female & $47.6 \%$ \\
\hline Residence Area & Rural & $21.6 \%$ \\
& Semi-Urban & $41.2 \%$ \\
& Urban & $37.2 \%$ \\
\hline Owning a smartphone & Yes & $94.8 \%$ \\
& No & $5.2 \%$ \\
\hline Technology Experience & $0-1$ year & $18.8 \%$ \\
& 2 years & $20.4 \%$ \\
& 3 years & $16.4 \%$ \\
& 4 or more than 4 years & $44.4 \%$ \\
\hline Frequency of social media use per day & Once a day & $0.5 \%$ \\
& $2-5$ times a day & $33.3 \%$ \\
& $6-10$ times a day & $17.8 \%$ \\
& $10+$ times a day & $48.4 \%$ \\
\hline
\end{tabular}

Source: Sample Survey 2020

In this study, students' addiction to social media was measured using the Bergen Social Media Addiction Scale in which

those who had scored more than the cutoff were recognized as social media addicts.
Table 1 represents the descriptive statistics of the present study. A higher proportion of females were included in the sample and the majority were from semi-urban areas. According to the statistics, almost 95 percent of the students owned a smartphone. Furthermore, considering the technological experience of students, the highest proportion was reported for the category of 4 or more than 4 years, and considering the frequency of use, the highest proportion was reported to be more than 10 times a day.

Figure 2: Social Media Addiction

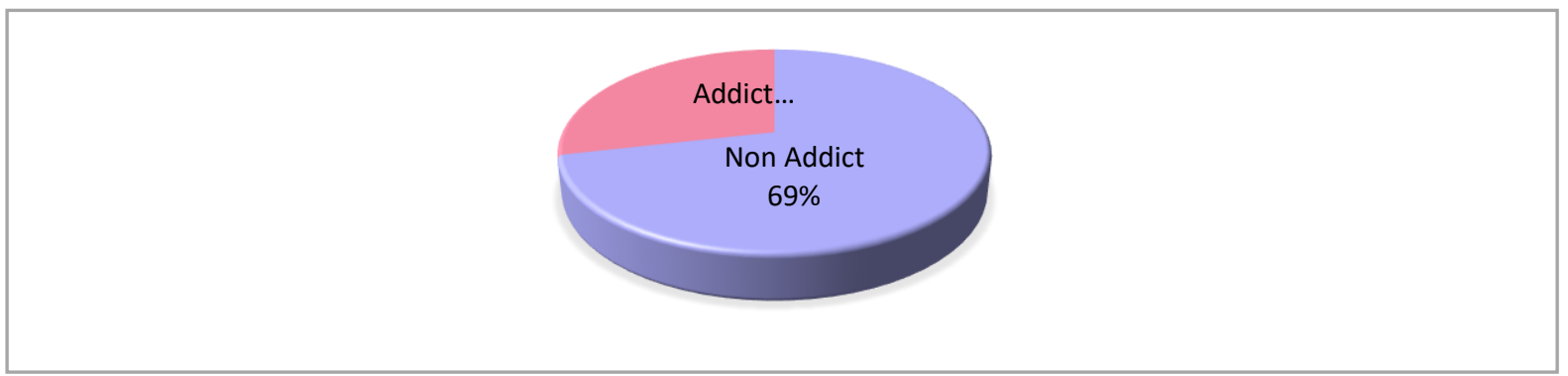

Source: Sample Survey 2020

Social media-addicted students among the selected respondents were recorded as 31 percent. Out of the total respondents, 69 percent were non-addicts. Therefore, the majority of respondents were non-addicts. Elsewise, it can be explained that on average, one in three students were addicted to social media.
The G.C.E. Advanced Level curriculum consists of mainly five subject streams. There may be having significant differences in addiction levels among the students of different streams. Figure 3 shows how the social media addiction of students differs based on the subject stream of study.

\section{Figure 3: Social Media Addiction based on Subject stream}

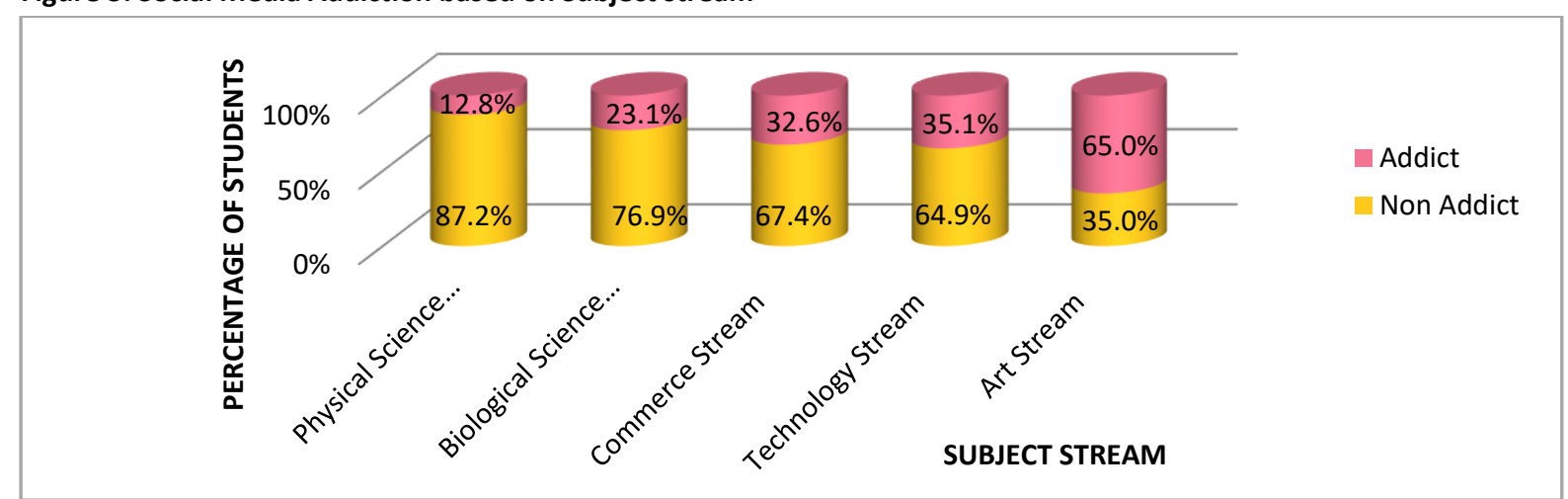

Source: Sample Survey 2020 
According to figure 3, 65 percent of the students in the art stream were addicted to social media. Hence, it is clear that the art stream has the highest proportion of addicted students. 35.1 and 32.6 percent of students in the technology stream and commerce stream were social media addicts respectively. In contrast, only 12.8 percent of students studying in the physical science stream are addicted to social media, recording the lowest proportion of addiction.
Based on whether a student owns a smartphone or not, it may influence on social media addictive behaviors of students. The percentages of students based on possessing a smartphone and corresponding addictiveness are illustrated in figure 4.

\section{Figure 4: Social Media Addiction based on Owning a Smartphone}

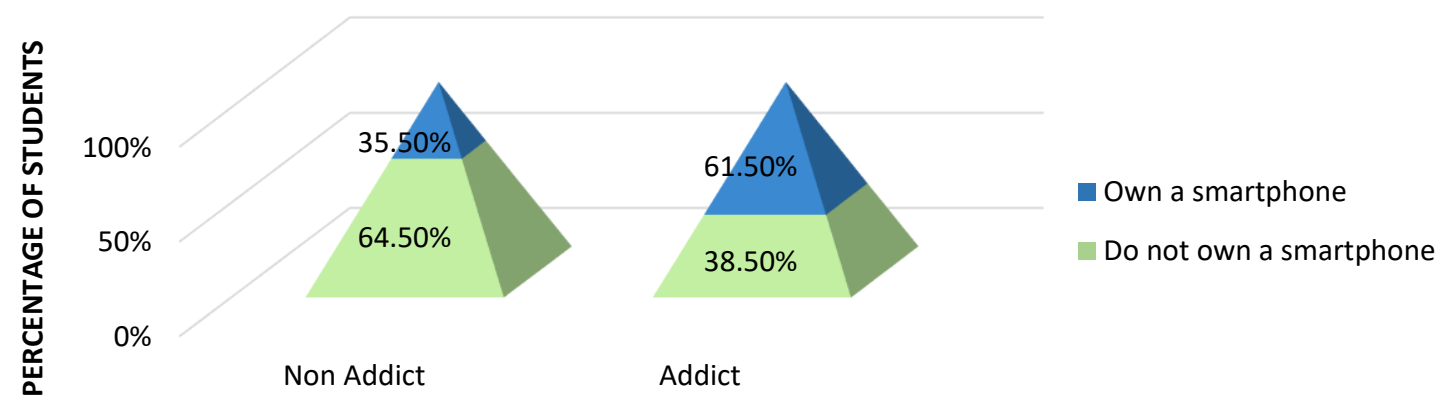

SOCIAL MEDIA ADDICTION

Source: Sample Survey 2020

According to figure 4, among the social media-addicted students, 61.5 percent owned a smartphone while 38.5 percent did not. This implies that a majority of social media-addicted students own a smartphone. Among the nonaddicts, 64.50 percent did not own a smartphone which implies that the majority of non-addicted students did not own a smartphone. As a result, the implication that a student in possession of a smartphone is more prone to addiction is obvious.

When concerning Advanced Level students, parents' social media use may execute a key role in the social media utilization of students. Figure 5 represents how parents' engagement in social media may contribute to their child's addiction level.

Figure 5: Social Media Addiction based on Parents' use of Social Media

\begin{tabular}{|c|c|c|c|}
\hline & & & \\
\hline
\end{tabular}

Source: Sample Survey 2020

Figure 5 clearly shows that only 35.20 percent of the students whose parents do not use social media were addicted while 46.80 percent of the students whose parents use social media were addicted. From the total sample, 64.80 percent of the students were non-addicts whose parents did not use social media. On the other hand, 53.20 percent of students whose parents engage in social media actively, were not addicted to social media. When comparing the two categories, the children whose parents use social media reported a higher percentage of social media addiction. This Figure 6: Time spent in Social Media by Female and Male Students

\section{FEMALE}

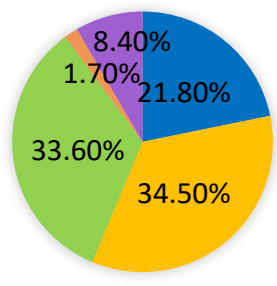

- less than 30 minutes

30-60 minutes

1-3 hours

4-5 hours

more than 5 hours implies that parents' social media use executes a key role in the social media utilization of students.

Considering the social media usage behaviors, time spent in social media among male and female students showed significant differences. Figure 6 illustrates how time spent on social media per day contrasts among female and male students. 
Among female students, 34.5 percent use social media for 30 to 60 minutes per day while among male students, 46.6 percent use social media for 1 to 3 hours. Similarly, among the students who use social media for 4 to 5 hours, the male proportion is higher than the females. There is 21.8 percent of females using social media for less than 30 minutes while males were only 6.9 percent. Comparing the two pie charts, it is that the time spent on social media by female students is comparatively lower than that of male students.

Social media addiction among the students may vary based on their parents' working status. Parents' working status is whether father, mother, both parents or none of them working. Figure 7 is regarding the effect of social media addiction based on parents' working status.

Figure 7: Distribution of Social Media Addiction based on Parents' Working Status
As per figure 7, when considering the addicted students, 71.10 percent of students with parents both working were addicted to social media. 33.3 percent of students whose only mother worked were addicted to social media while only 31.3 percent of whose father worked were addicted. The highest proportion of addicted students was recorded in the category of both parents working. This may be a result of parents having insufficient time to spend with their children when they have to work. As a consequence of children's isolation, they may lean towards addictive social media behaviors.

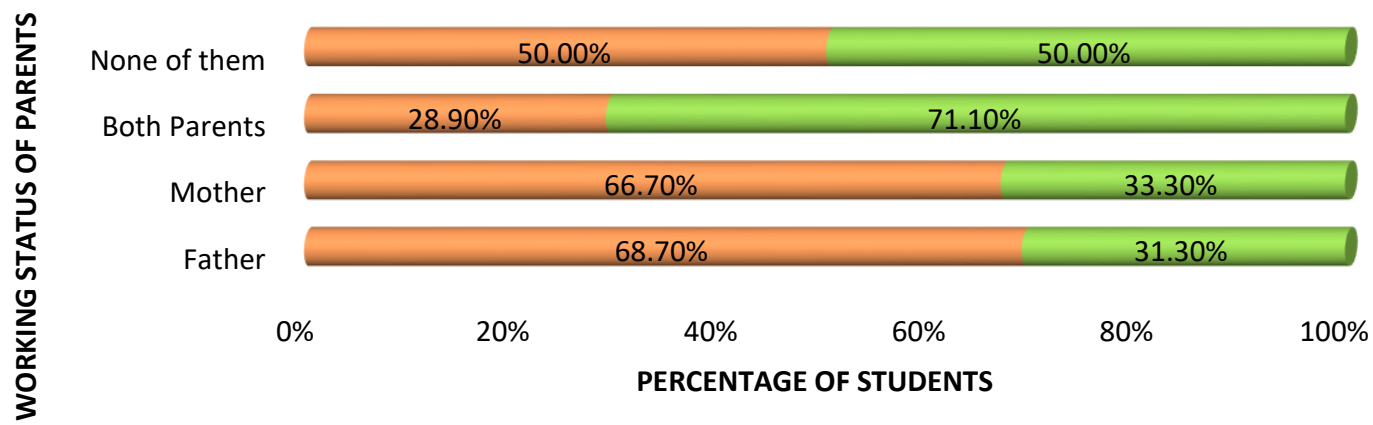

Non Addict $\quad$ Addict

Source: Sample Survey 2020

There were altogether 23 explanatory variables computed by questions in the questionnaire among which 15 questions were used to measure the variables parent influence, peer influence, online interpersonal relationships, entertainment, parents' use of social media, and satisfaction. When multicollinearity was checked among those 15 questions, it was found that they were forming significant relationships. Three sets of collinear questions were identified as a result. As the first set, seven questions used to measure the variables parent influence, peer influence, and parents' use of social media were identified as collinearity components as represented by table 2 .

Table 2: Eigen Analysis for collinear variables: Set 1

\begin{tabular}{lrrr}
\hline Component & Total & $\begin{array}{r}\text { Initial Eigenvalues } \\
\text { \% of Variance }\end{array}$ & Cumulative \% \\
\hline $\mathbf{1}$ & 3.349 & 47.836 & 47.836 \\
$\mathbf{2}$ & 1.320 & 18.855 & 66.692 \\
$\mathbf{3}$ & .825 & 11.779 & 78.470 \\
$\mathbf{4}$ & .615 & 8.786 & 87.256 \\
$\mathbf{5}$ & .551 & 7.878 & 95.134 \\
$\mathbf{6}$ & .331 & 4.734 & 99.868 \\
$\mathbf{7}$ &. $\mathbf{0 0 9}$ &. $\mathbf{1 3 2}$ & $\mathbf{1 0 0 . 0 0 0}$ \\
\hline
\end{tabular}

Source: Sample Survey 2020

When considering eigenvalues, there were only two eigenvalues greater than one. A common rule of thumb is to select components whose eigenvalues greater than unity to decide the number of factors to extract. But when considering the cumulative variance explained by the first two components, it was only 66.692 percent and could not even

\section{Table 3: Factor Loadings}

reach 80 percent. By considering the first three components together, it carried a cumulative variance of 78.470 percent and that value was very close to 80 percent. Therefore, the next component was also considered for the creation of new variables. Hence, the number of factors extracted for this set of components was 3 .

\begin{tabular}{lrrrr}
\hline Rotated Component Matrix & \multicolumn{3}{c}{} & \\
\cline { 2 - 3 } & \multicolumn{3}{c}{ Component } & Newly Generated \\
\cline { 2 - 3 } Variables \\
\hline My parents have discussed with me what I've been doing online & .202 & .365 & .676 & \\
My parents have restricted me on using some social media sites & .194 & .081 & .882 & \\
My parents complain when I do something in social media that & .205 & .055 & .874 & Parent Influence \\
they dislike & & & & \\
I talk with my friends about social media posts and profiles & .736 & .024 & .148 & \\
\hline
\end{tabular}




\begin{tabular}{|c|c|c|c|c|}
\hline $\begin{array}{l}\text { My friends complain when I do something in social media that } \\
\text { they dislike }\end{array}$ & .921 & .199 & .192 & Peer Influence \\
\hline My parents use social media frequently & .186 & .924 & .181 & Parent and Peer Utili- \\
\hline
\end{tabular}

Source: Sample Survey 2020

Table 3 shows the factor loadings and the newly defined names of the variables. As stated, the new variables generated were parent influence, peer influence, and parent and peer utilization of social media.

Table 4 represents the factor loadings for the second set of collinear questions identified. After performing factor analysis, two new variables were generated instead of the 4 original components by considering the factor loadings. They were online interpersonal relationships and social interaction

Table 4: Factor Loadings

\begin{tabular}{|c|c|c|c|}
\hline \multirow[t]{3}{*}{ Rotated Component Matrix } & \multirow{2}{*}{\multicolumn{2}{|c|}{ Component }} & \multirow{3}{*}{$\begin{array}{l}\text { Newly Generated } \\
\text { Variables }\end{array}$} \\
\hline & & & \\
\hline & 1 & 2 & \\
\hline $\begin{array}{l}\text { How many friends/ followers do you have in your social media ac- } \\
\text { counts? }\end{array}$ & .057 & .720 & Online Interpersonal \\
\hline $\begin{array}{l}\text { How many relationships do you have that are maintained exclusively } \\
\text { via social media? }\end{array}$ & .108 & .987 & Relationships \\
\hline I prefer friendships on social media than friendships in real life & .711 & .014 & Social Interaction \\
\hline I use social media to interact with the society well & .580 & .174 & \\
\hline
\end{tabular}

Source: Sample Survey 2020

As per the loadings of the rotated loading matrix of the third set of collinear questions regarding the enjoyment and satisfaction of using social media, two factors were built. They

are defined under the factor loadings as entertainment and satisfaction as stated by table 5 .

Table 5: Factor Loadings

\begin{tabular}{|c|c|c|c|}
\hline \multicolumn{4}{|c|}{ Rotated Component Matrix } \\
\hline & \multicolumn{2}{|c|}{ Component } & \multirow{2}{*}{$\begin{array}{l}\text { Newly Generated } \\
\text { Variables }\end{array}$} \\
\hline & 1 & 2 & \\
\hline Using social media sites makes my life more interesting and fun & .560 & .605 & \\
\hline I think my life would be empty, boring and joyless without social media & .048 & .947 & Entertainment \\
\hline Level of satisfaction of using Social media. & .941 & .143 & Satisfaction \\
\hline How happy are you with using social media & .951 & .121 & \\
\hline
\end{tabular}

Source: Sample Survey 2020

From the factor analysis, altogether 7 new independent variables were generated as a result; Parent influence, Peer influence, Parent and peer utilization of social media, online interpersonal relationships, Social interaction, Entertainment, and Satisfaction.

Before fitting the binary logistic regression model, it was checked whether there were any associations between explanatory variables and the dependent variable using Pearson correlation analysis and Chi-square test. Multicollinearity was checked between the explanatory variables selected Table 6: Best Fitted Model for Total students

\begin{tabular}{lrrrrrr}
\hline Parameter & B & S.E. & Wald & df & Sig. & Exp(B) \\
\hline Entertainment & 1.110 & .194 & 32.613 & 1 & .000 & 3.033 \\
Peer Influence & .925 & .188 & 24.223 & 1 & .000 & 2.522 \\
Owning a Smartphone (yes) & 1.109 & .329 & 11.371 & 1 & .001 & 3.032 \\
Constant & -1.606 & .253 & 40.415 & 1 & .000 & .201 \\
\hline
\end{tabular}

Source: Sample Survey 2020

Logit $P(x)=-1.606+1.110$ Entertainment +0.925 Peer Influence +1.109 Owning a Smartphone

According to the binary logistic regression model, the variables entertainment, Peer Influence, and Owning a Smartphone were significant. If entertainment is increased for the model fitting from the previous step by occupying Chi-square test, One-way ANOVA, and Pearson correlation analysis. The researcher fitted several models with selected variables and corresponding $\mathrm{G} 2$ values were examined to identify the best-fitted model. After fitting the best fitted biquacy) of the model was checked by the Hosmer-Lemeshow test.

The results of the Binary Logistic Regression Model for Total Students' Social Media Addiction are given in table 6.

by one unit, then the social media addiction of students will be increased by 37.85 percent when all other factors are kept constant. If peer influence is increased by one unit, then the social media addiction of students will be increased by 33.6 percent when all other factors are kept constant. If nary logistic regression model, the goodness of fit (ade- 
we compare the respondents who do not own a smartphone, the social media addiction of students who own a smartphone will be increased by 37.82 percent when all other factors are constant.

After fitting the best fitted binary logistic regression model, the goodness of fit of the model was checked. For that Hosmer-Lemeshow test was applied to the best-fitted model as stated in table 5. According to the Hosmer-Lemeshow test, the $p$-value of 0.346 was greater than the significant value of 0.05 which concludes that the model is adequately fitted.

Peer influence was found as a significant factor in the study of Kristianto (2017) and it has been identified as one of the Table 7: Best Fitted Model for Female students

\begin{tabular}{lrrrrrr}
\hline Parameter & B & S.E. & Wald & df & Sig. & Exp(B) \\
\hline Online interpersonal relationships & 1.246 & .293 & 18.113 & 1 & .000 & 3.478 \\
Parent and peer utilization of social media & .736 & .275 & 7.147 & 1 & .008 & 2.088 \\
Constant & -.767 & .244 & 9.919 & 1 & .002 & .464 \\
\hline
\end{tabular}

Source: Sample Survey 2020

Logit $\mathbf{P}(\mathbf{x})=-\mathbf{0 . 7 6 7}+1.246$ Online Interpersonal Relationships + 0.736 Parent and Peer Utilization of Social Media

According to the best-fitted model of female students, if an online interpersonal relationship is increased by one unit, then the social media addiction of female students will be increased by 61.75 percent when all other factors are kept constant. If the parent and peer utilization of social media is increased by one unit, and then the social media addiction of students will be increased by 49.22 percent when all other factors are kept constant.

Table 8: Best Fitted Model for Male students

\begin{tabular}{lrrrrrr}
\hline Parameter & B & S.E. & Wald & df & Sig. & Exp(B) \\
\hline Peer Influence & 1.137 & .279 & 16.601 & 1 & .000 & 3.116 \\
Subject stream & & & 13.066 & 4 & .011 & \\
Biological science stream (1) & .369 & .914 & .163 & 1 & .686 & 1.447 \\
Commerce stream (2) & 1.133 & .668 & 2.882 & 1 & .090 & 3.106 \\
Technology stream (3) & 1.968 & .804 & 5.988 & 1 & .014 & 7.154 \\
Art stream (4) & 3.231 & .983 & 10.814 & 1 & .001 & 25.306 \\
Owning a smartphone(yes) & 1.150 & .486 & 5.608 & 1 & .018 & 3.159 \\
Constant & -2.649 & .633 & 17.488 & 1 & .000 & .071 \\
\hline
\end{tabular}

Source: Sample Survey 2020

Logit $P(x)=-2.649+1.137$ Peer Influence + 1.968Technology stream +3.231 Art stream +1.150 Owning a Smartphone

If peer influence is increased by one unit, then the social media addiction of male students will be increased by 18.06 percent when all other factors are kept constant. According to the subject stream, if we compare the respondents of the physical science stream, the social media addiction of students who are in the technology stream is increased by 33.60 percent when all other factors are constant. If we compare the respondents of the physical science stream, the social media addiction of students who are in the arts stream is increased by 64.15 percent when all other factors are constant. According to owning a smartphone, if we compare the respondents who do not own a smartphone, the social media addiction of students who own a smartphone will be increased by 18.25 percent when all other factors are constant.

After fitting the best fitted binary logistic regression model for male students, the goodness of fit of the model was checked. For that Hosmer-Lemeshow test was applied to the best-fitted model as stated in table 9. According to the Hosmer-Lemeshow test, the $p$-value of 0.271 was greater than strongest predictors of social media addiction in the study of Steers, Moreno, and Neighbors (2016) as well. On the contrary, none of the studies were found with owning a smartphone as a significant factor. In the study of Otu (2015) regarding the social media addiction among the students of nette, Howard, Ceballos, Dailey, Lu, and Grimes (2019) was found that the majority of the students use their social media accounts for entertainment.

The output of the binary logistic regression model for female students' social media addiction is given in table 7.

After fitting the best fitted binary logistic regression model for female students, the goodness of fit of the model was checked. For that Hosmer-Lemeshow test was applied to the best-fitted model as stated in table 7. According to the Hosmer-Lemeshow test, the $p$-value of 0.435 was greater than the significant value of 0.05 which concludes that the model is adequately fitted. the variables peer influence, subject stream, and owning a smartphone were significant for male students' social media addiction. the University of Ghana and in the study of Robinson., Bon-

According to Table 8 of the binary logistic regression model, the significant value of 0.05 which concludes that the model is adequately fitted.

\section{CONCLUSION}

The conclusions derived by data presentation emphasized that on average, one in three students were addicted to social media. Further, the majority among the social media-addicted students owned a smartphone. Concerning the working status of parents, the highest proportion of addicted students was recorded in the category of both parents working. This suggests that as a result of parents having less time to spend with their children, the latter becomes more prone to social media addiction. Additionally, it was revealed that time spent on social media by female students is comparatively lower than that of males.

It was revealed by the binary logistic regression model that peers influence, entertainment, and owning a smartphone positively affected the total students' social media addiction. Social media has presently become one of the main sources of entertainment in the minds of students. They believe social media provides a higher valued experience compared with other forms of entertainment. The factor 'peer influence' was also revealed as highly influential on a student's social media addiction. According to the study, peer 
influence is at the extent to which peers or friends interact and discuss social media-related things most often (posts, profiles, etc.). In particular, it was noted that the more the younger adolescents talk about social media-related matters with peers, the more likely they might get addicted to social media. Similarly, 'owning a smartphone' as a technological factor, displayed a major influence on student addiction. In recent times, mobile technology has drastically changed individual behaviors, especially among adolescents. Therefore, the study revealed that social media addiction among the students owning a smartphone was comparatively higher than those who did not own a smartphone.

When it comes to female students, parent and peer utilization of social media and online interpersonal relationships were identified as significant factors. Parent and peer utilization, engagement in social media activities, and online interpersonal relationships have positively influenced the social media addiction of female students. Both the significant variables were derived as a result of factor analysis. Similarly, peer influence, subject stream, and owning a smartphone were identified as influential factors for male students' addiction. It was further revealed that male students who were studying in the art and technology streams had a higher possibility for addiction compared to that of the physical science stream.

The overall research provides important recommendations for parents, teachers, and policymakers on possible actions to prevent addiction. Parents should avoid giving smartphones to their children until they are matured enough and they should also dedicate more time to their children. Parents should manage their child's screen time and encourage them to start doing so on their own. Also, students should be monitored by teachers and parents on how they use these platforms and enlighten them about the influence of social media on their studies. Policymakers should enact new policies and regulations to restrict students' access to unnecessary social media networks and new platforms should be created to avoid setbacks in the students' academic performance. Moreover, the responsibility of increasing public awareness on social media addiction should be undertaken by the media, education, and health authorities.

\section{REFERENCES}

Al-Menayes, J. J. (2015). Social media use, engagement, and addiction as predictors of academic performance. International Journal of Psychological Studies, 7(4), 86-94.

Andreassen, C. S., Billieux, J., Griffiths, M. D., Kuss, D. J., Demetrovics, Z., Mazzoni, E., \& Pallesen, S. (2016). The relationship between addictive use of social media and video games and symptoms of psychiatric disorders: A large-scale cross-sectional study. Psychology of Addictive Behaviors, 30(2), 252.

Athukorala, A. W. V. (2018). Factors Affecting Use of Social Media by University Students: A Study at the Wuhan University of China. Journal of the University Librarians Association of Sri Lanka, 21(2). 44-72.

Bányai, F., Zsila, Á., Király, O., Maraz, A., Elekes, Z., Griffiths, M. D., Andreassen, S.C., \& Demetrovics, Z. (2017). Problematic social media use: Results from a large-scale nationally representative adolescent sample.Plos One, 12(1), 1-13.

Bjornsen, C. (2018). Social media use and emerging adulthood. Prehod v odraslost: Sodobni trendi in raziskave, 193-223.

Boyd, D. M. (2008). ELLISON. Nicole B. Social Network Sites: Definition, history, and scholarship. Journal of Computer-Mediated Communication, 13, 210-230.

Data Reportal (2020). Retrieved October 2,2020, from Digital 2020 Sri Lanka: https://datareportal.com/reports/digital-2020-sri-lanka

Davis, F. D. (1989). Perceived usefulness, perceived ease of use, and user acceptance of information technology. MIS Quarterly, 13(3), 319-340.
Deng, L., \& Tavares, N. J. (2013). From Moodle to Facebook: Exploring students' motivation and experiences in online communities. Computers \& Education, 68, 167-176

Eraslan-Capan, B. (2015). Interpersonal sensitivity and problematic Facebook use in Turkish university students. The Anthropologist, 21(3), 395-403.

Hawi, N. S., \& Samaha, M. (2017). The relations among social media addiction, self-esteem, and life satisfaction in university students. Social Science Computer Review, 35(5), 576-586.

Hong, F. Y., Huang, D. H., Lin, H. Y., \& Chiu, S. L. (2014). Analysis of the psychological traits, Facebook usage, and Facebook addiction model of Taiwanese university students. Telematics and Informatics, 31(4), 597-606.

Hou, Y., Xiong, D., Jiang, T., Song, L., \& Wang, Q. (2019). Social media addiction: Its impact, mediation, and intervention. Cyberpsychology: Journal of psychosocial research on cyberspace, 13(1), 1-17.

Kane, G. C., Alavi, M., Labianca, G., \& Borgatti, S. P. (2014). What's different about social media networks? A framework and research agenda. MIS Quarterly, 38(1), 275-304.

Kavčič, T., Zupančič, M., Levpušček, M. P., Poredoš, M., \& Bjornsen, C. (2019). Personal Correlates Of Problematic Types Of Social Media And Mobile Phone Use In Emerging Adults. Human Technology, 15(2), 257-260.

Kietzmann, J. H., Hermkens, K., McCarthy, I. P., \& Silvestre, B. S. (2011). Social media? Get serious! Understanding the functional building blocks of social media. Business Horizons, 54(3), 241-251.

Koc, M., \& Gulyagci, S. (2013). Facebook addiction among Turkish college students: The role of psychological health, demographic, and usage characteristics. Cyberpsychology, Behavior, and Social Networking, 16(4), 279-284.

Kristianto, B. (2017). Factors Affecting Social Network Use by Students in Indonesia. Journal of Information Technology Education, 16(1), 69103.

Lewis, M. (2005). The Child and Its Family: The Social Network Model. Human Development, 48(1-2), 8-27.

Livingstone, S. (2014). Developing social media literacy: How children learn to interpret risky opportunities on social network sites. Communications, 39(3), 283-303.

Lwin, M. O., Li, B., \& Ang, R. P. (2012). Stop bugging me: An examination of adolescents' protection behavior against online harassment. Journal of adolescence, 35(1), 31-41.

Mediakix (n.d.). 10 Social Media Marketing Statistics To Know In 2018. Retrieved September 23, 2020, from https://mediakix.com/blog/10top-social-media-marketing-statistics-to-know-2017/

Ministry of Education (n.d.). Retrieved October 28,2020, from Annual School Census of Sri Lanka FinalReport-2018: http://www.statistics.gov.lk/Education/Staticallnformation/SchoolCensus/2018

NapoleonCat (n.d.). Retrieved October 23, 2020, from Facebook users in Sri Lanka March 2020: https://napoleoncat.com/stats/facebook-users-in-sri_lanka/2020/03

Oktan, V. (2015). Problematic internet use, loneliness, and perceived social support among university students. Kastamonu Education. Journal, 23(1), 281-292.

Otu, A. A. (2015). Social media addiction among students of the University of Ghana (Doctoral dissertation, University of Ghana).

Robinson, A., Bonnette, A., Howard, K., Ceballos, N., Dailey, S., Lu, Y., \& Grimes, T. (2019). Social comparisons, social media addiction, and social interaction: An examination of specific social media behaviors related to major depressive disorder in a millennial population. Journal of Applied Biobehavioral Research, 24(1), 121-158.

Samaha, M., \& Hawi, N. S. (2016). Relationships among smartphone addiction, stress, academic performance, and satisfaction with life. Computers in Human Behavior, 57, 321-325.

Savci, M., \& Aysan, F. (2016). Relationship between impulsivity, social media usage, and loneliness. Educational Process: International Journal, 5(2), 106

Shahghasemi, E., \& Emamzadeh, Z. (2019). Factors Influencing Social Media Usage in the US. Journal of Cyberspace Studies, 3(1), 5-22.

Shin, W., \& Ismail, N. (2014). Exploring the role of parents and peers in young adolescents' risk-taking on social networking sites. Cyberpsychology, Behavior, and Social Networking, 17(9), 578-583. 
Steers, M. L. N., Moreno, M. A., \& Neighbors, C. (2016). The influence of social media on addictive behaviors in college students. Current addiction reports, 3(4), 343-348.

Sushko, O. (2020). What Is Online Privacy? This Is Your Human Right Claro. Retrieved from https://clario.co/blog/live-secured/what-isonline-privacy/

Telecommunications Regulatory Commission of Sri Lanka(n.d.) Retrieved October 28, 2020, from Statistics: http://www.trc.gov.lk/2014-05-13-03-56-46/statistics.html

The Guardian(n.d.). Teenage girl kills herself 'after Instagram poll' in Malaysia. Retrieved October 28, 2020, from https://www.theguard ian.com/world/2019/may/15/teenage-girlkills-herself-after-instagram-poll-in-malaysia

Tutgun-Unal, A. (2015). Social media addiction: A research on university students (Unpublished doctoral dissertation). Marmara University, Istanbul, Turkey, 20(2), 155-168.

Tyagi, V., \& Soni, M. R. T.(2019) Factors affecting the use of Social Media by students - A study of Delhi NCR, 4(11), 53-58.

Yahya, Y., \& Rahim, N. Z. A. (2017, July). Factors Influencing Social Networking sites Addiction among the adolescents in Asian Countries. In PACIS, 241. 
